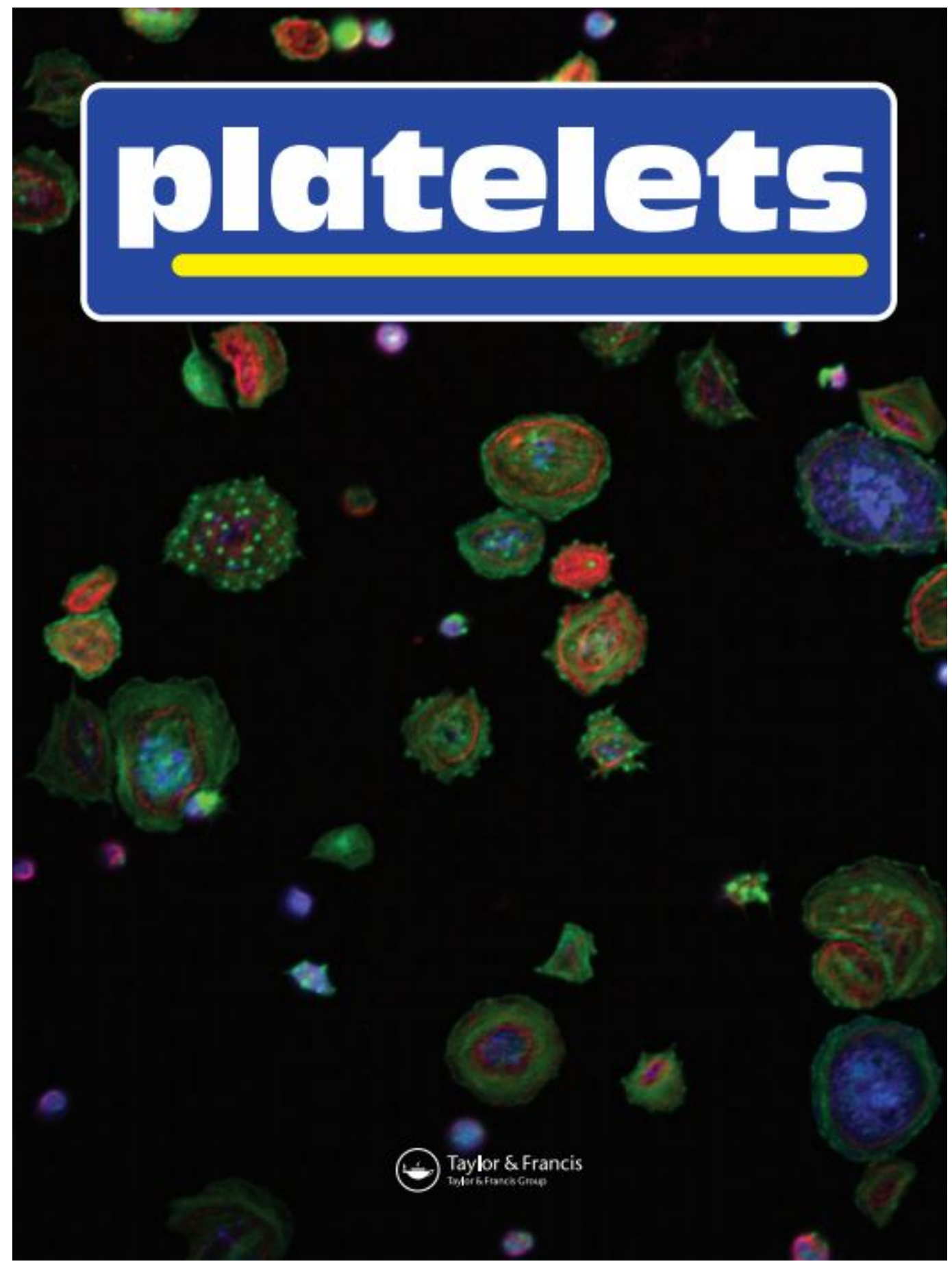

Plasma levels of the soluble form of the FcyRIIa receptor vary with receptor polymorphisms and are elevated in rheumatoid arthritis 


\begin{tabular}{|r|l|}
\hline Manuscript ID & CPLA-2019-0040.R1 \\
\hline Manuscript Type: & Original Article \\
\hline Date Submitted by the & n/a \\
\hline Complete List of Authors: & $\begin{array}{l}\text { Qiao, Jianlin; Xuzhou Medical College, } \\
\text { Dunne, Eimear; Royal College of Surgeons in Ireland, Molecular and } \\
\text { Cellular Therapeutics } \\
\text { Wines, Bruce; Burnet Institute } \\
\text { Kenny, D; Royal College of Surgeons in Ireland, } \\
\text { McCarthy, Geraldine; Mater Misericordiae University Hospital } \\
\text { Hogarth, P.Mark; Burnet Institute } \\
\text { Xu, Kailin; The Affiliated Hospital of Xuzhou Medical University, } \\
\text { Department of Hematology } \\
\text { Andrews, Robert; Monash University, Australian Centre for Blood } \\
\text { Diseases } \\
\text { Gardiner, Elizabeth; Australian National University, Cancer Biology and } \\
\text { Therapeutics }\end{array}$ \\
\hline Keywords: & \begin{tabular}{l} 
Receptor, FcyRIIa, metalloproteinase, polymorphism \\
\hline
\end{tabular} \\
\hline
\end{tabular}

\section{SCHOLARONE ${ }^{m}$ \\ Manuscripts}




\title{
Plasma levels of the soluble form of the Fc $\gamma$ RIIa receptor vary with receptor polymorphisms and are elevated in rheumatoid arthritis
}

\author{
Jianlin Qiao, ${ }^{1,2,3}$ Eimear Dunne, ${ }^{4}$ Bruce Wines, ${ }^{5}$ Dermot Kenny, ${ }^{4}$ Geraldine M. McCarthy, ${ }^{6}$ \\ P. Mark Hogarth, ${ }^{5}$ Kailin Xu, ${ }^{2,3}$ Robert K. Andrews ${ }^{1 \#}$ and Elizabeth E. Gardiner ${ }^{7 \#}$ \\ ${ }^{1}$ Australian Centre for Blood Diseases, Monash University, Melbourne, Australia; ${ }^{2}$ Blood \\ Disease Institute, Xuzhou Medical University, Xuzhou, China; ${ }^{3}$ Department of Hematology, \\ the Affiliated Hospital of Xuzhou Medical University, Xuzhou, China; ${ }^{4}$ Molecular \& \\ Cellular Therapeutics, Royal College of Surgeons in Ireland, Dublin, Ireland; ${ }^{5}$ Centre for \\ Biomedical Research, Burnet Institute, Melbourne, Australia; ${ }^{6}$ Mater Misericordiae \\ University Hospital, Dublin, Ireland; ${ }^{7}$ ACRF Department of Cancer Biology and \\ Therapeutics, John Curtin School of Medical Research, The Australian National University, \\ Canberra, Australia
}

\section{Running title: Soluble Fc $\gamma$ RIIa levels and polymorphisms}

\#These authors contributed equally

\section{Correspondence to}

Professor Elizabeth E. Gardiner, ACRF Department of Cancer Biology and Therapeutics, John Curtin School of Medical Research, Australian National University, 131 Garran Rd, Canberra, ACT 2601 Australia.

Email: elizabeth.gardiner@anu.edu.au

Word count 3627 (text excluding abstract, figure legends and references) Abstract 197 


\begin{abstract}
Soluble forms of the low-affinity immunoglobulin receptor Fc $\gamma$ RIIa (sFc $\gamma$ RIIa) lacking the cytoplasmic tail have been reported in plasma however the mechanism and functional consequences are unknown. This study aimed to evaluate mechanisms of FcyRIIa release compared to GPVI release from platelets, and examine whether genetic polymorphisms at positions 27 and 131 within FcyRIIa correlate with platelet FcyRIIa stability and function. Enzyme-linked immunosorbent assays (ELISAs) were used to measure plasma sFc $\gamma$ RIIa and sGPVI levels. Fc $\gamma$ RIIa genotype at positions 27 and 131 was evaluated. sFc $\gamma$ RIIa levels were not significantly different between non- $131 \mathrm{HH}$ and $131 \mathrm{HH}$, but were significantly lower in $27 \mathrm{~W} / 131 \mathrm{H}$ than non-27W/131H. Treatment of platelets with aggregated immunoglobulin (Ig) G induced release of FcyRIIa and GPVI, but only sGPVI release was statistically significant, required functional Fc $\gamma$ RIIa, and was blocked by inhibitors of signalling pathways and metalloproteinases. This indicated that sFcrRIIa was not released from platelets by metalloproteolysis. sFcyRIIa levels were not correlated with sGPVI levels in healthy individuals however levels of sFc $\gamma$ RIIa and sGPVI in plasma from patients with rheumatoid arthritis (RA) were significantly elevated above levels found in healthy individuals. Elevated level of sFc $\gamma$ RIIa in RA patients may reflect active immune-based arthritis and be predictive of active inflammation.
\end{abstract}

Key words: Fc $\gamma$ RIIa; polymorphism; platelet; GPVI; rheumatoid arthritis 


\section{Introduction}

FcyRIIa is the only IgG Fc-receptor expressed on the surface of platelets but is also found on neutrophils, monocytes, and macrophages $[1,2]$. It is a low affinity receptor for Ig unique to humans and non-human primates, and composed of two extracellular Ig-like domains, containing the binding site for the Fc portion of IgG, a transmembrane domain and a cytoplasmic tail that contains a binding site for calmodulin and an immunoreceptor tyrosinebased activation motif (ITAM) domain that is essential for signal transduction and platelet activation. Both alleles of the gene encoding Fc $\gamma$ RIIa are transcribed and translated, generating equal amounts of protein. A polymorphism, resulting from the amino acid substitution from arginine $(\mathrm{R})$ to histidine $(\mathrm{H})$ at position 131 in the second Ig-like domain of FcyRIIa has been previously shown to alter the binding affinity of the receptor for different IgG subclasses. FcyRIIa-H131 binds to human IgG2 with higher affinity than Fc $\gamma$ RIIa-R131; however, FcyRIIa-R131 has a higher binding affinity for murine IgG1 than FcyRIIa-H131 [3-5]. Increasing evidence [6-9] demonstrated that the Fc $\gamma$ RIIa polymorphism (H/R131) was associated with immune diseases due to different IgG binding affinity. A further polymorphism in FcyRIIa at position 27 (glutamine or tryptophan) was shown not to be linked with the polymorphism at position 131 and in isolation did not affect receptor function or IgG binding [10] but may have some impact on FcrRIIa signalling events [11].

Previous studies in vitro demonstrated that engagement of either Fc $\gamma$ RIIa or GPVI on platelets by their respective ligands induced both intracellular calpain-mediated cleavage of Fc $\gamma$ RIIa and extracellular metalloproteinase-mediated ectodomain shedding of GPVI [12]. Increased levels of sGPVI are also observed in patients with immune thrombocytopenia [13, 14] and in patients with seropositive rheumatoid arthritis [15]. It is postulated that increased release of sGPVI could be induced by engagement of platelet receptor FcyRIIa by the Fc 
portion of anti-platelet autoantibodies in the plasma of ITP patients. The cytoplasmic domain of FcyRIIa binds calmodulin [12], a hallmark of many metalloproteolytically shed membrane receptors including GPVI [16], GPV [17] and L-selectin [18]. Two Fc $\gamma$ RIIa transcripts (with or without the transmembrane domain encoding exon, termed Fc $\gamma$ RIIa1 and Fc $\gamma$ RIIa2 respectively), resulting from alternative RNA splicing, have been found in human platelets and a megakaryocytic cell line [19]. A third transcript, Fc $\gamma$ RIIa3 with a 19-amino acid cytoplasmic insertion was identified in peripheral blood mononuclear cells [20]. Further, there are other transcript variants (X1 to X10) which are predicted by automated computational analysis. Soluble forms of Fc $\gamma$ RIIa (Fc $\gamma$ RIIa2) reported in serum samples from healthy individuals and patients with chronic lymphocytic leukaemia are released from thrombin-activated human platelets [21] and megakaryocyte cell lines [22]. Activated neutrophils from systemic lupus erythematosus patients demonstrated a serine proteinase-dependent cleavage of Fc $\gamma$ RIIa that was correlated with markers of disease severity and complement activation [23]. However, the mechanism by which Fc $\gamma$ RIIa is released from blood cells and whether ligand-induced release of FcyRIIa similar to that observed with GPVI shedding occurs in vivo has not been addressed.

This study aimed to evaluate the proteolytic mechanisms of Fc $\gamma$ RIIa release compared to GPVI release and examine whether genetic polymorphisms at positions 27 and 131 within Fc $\gamma$ RIIa correlate with platelet Fc $\gamma$ RIIa stability and function.

\section{Materials and Methods}

\section{Reagents}

$N$-ethylmaleimide (NEM), GM6001 (a broad-range hydroxamic acid-based metalloproteinase inhibitor), calmodulin inhibitor W7 (N-(6-aminohexyl)-5-chloro-1-aphthalenesulfonamide) 
and the membrane permeable calpain inhibitor E64d (L-3-carboxy-trans-2, 3-epoxypropionylL-leucylamido-(3-methyl) butane) were from Calbiochem (La Jolla, CA, USA). The hydroxamate-based inhibitor GI254023 has been previously described and characterized for preferential inhibition of ADAM10 over ADAM17 [24]. The Syk inhibitor, 2-(7-(3,4dimethoxyphenyl)-imidazo[1,2-c]pyrimidin-5-ylamino)-nicotinamide

dihydrochloride (BAY61-3606) was from Enzo Life Sciences (Farmingdale, NY, USA).

\section{Antibodies}

Anti-FcyRIIa monoclonal antibody 8.26 recognising a non-ligand binding region and HRPconjugated anti-FcyRIIa monoclonal antibody 8.7 recognising a ligand binding region within domain 2 have been described [25]. 14A2, which binds to tetraspanin CD151 and engages Fc $\gamma$ RIIa via its Fc domain, has been previously described [26, 27]. The anti-Fc $\gamma$ RIIa monoclonal antibody, IV.3 [28] was purified from hybridoma medium on protein A-Sepharose (Amersham, United Kingdom).

\section{Measurement of sFcrRIIa by ELISA}

The ELISA method for measuring sFcyRIIa was based on an established sandwich ELISA used to measure sGPVI in plasma [29]. Briefly, 96-well microtitre plates were coated with a “capturing” mouse monoclonal anti-FcyRIIa IgG $8.26(2 \mu \mathrm{g} / \mathrm{ml})$ in coating buffer $(0.05 \mathrm{M}$ bicarbonate, $\mathrm{pH} 9.6)$ overnight at $4^{\circ} \mathrm{C}$. Wells were washed six times with PBS (0.01 M sodium phosphate, $0.15 \mathrm{M}$ sodium chloride, $\mathrm{pH}$ 7.4) containing 0.2\% (v/v) Tween-20 (PBS-T), blocked with $1 \%(\mathrm{w} / \mathrm{v}) \mathrm{BSA}$ in PBS for $1 \mathrm{~h}$ at room temperature, then washed six times with PBS-T, before addition of samples diluted 10\% (v/v) in PBS in triplicate wells. After $1 \mathrm{~h}$ incubation at room temperature, wells were washed six times with PBS-T and the HRP-conjugated antiFc $\gamma$ RIIa monoclonal antibody 8.7 was added at $1 \mu \mathrm{g} / \mathrm{ml}(100 \mu \mathrm{l} /$ well $)$. After further $1 \mathrm{~h}$ incubation, wells were washed six times, $100 \mu \mathrm{l}$ of a one-half dilution of Super Signal ELISA 
Pico chemiluminescent substrate (Pierce Rockford IL, USA) was added and light emission (stable after $1 \mathrm{~min}$ ) was measured using a Wallac-Victor2 luminescence plate reader.

\section{Blood collection and platelet aggregation}

Experiments were carried out with the approval of the Monash University Standing committee on Ethics in Research Involving Humans, and informed consent was obtained from all participants in accordance with the Declaration of Helsinki. Platelet-rich plasma (PRP) was obtained from blood collected into $3.2 \%(\mathrm{w} / \mathrm{v})$ trisodium citrate and centrifuged for $20 \mathrm{~min}$ at $160 \times g$. Platelet-poor plasma (PPP) was obtained by centrifuging PRP at $1,350 \times g$ for 15 min. Washed platelets were prepared as previously described [30]. Platelet aggregation in citrated PRP was carried out at $37^{\circ} \mathrm{C}$ in a ChronoLog lumiaggregometer (Havertown, PA, USA) stirred at 900 rpm using PPP as control. Donors were of broad ethnicity and included donors with Caucasian, Asian, and Middle Eastern heritage. The donors were not preselected and all experimental work was completed before the genotype of each sample was revealed.

\section{DNA sequencing}

Genomic DNA was sequenced using the BigDye Terminator v1.1 cycle kit (Applied Biosystems, CA, USA). The sequenced region of the FcyRIIa protein included the two extracellular Ig domains. The sequences of primer 1 for DNA sequencing (the first Ig domain) were as follows: Forward: 5'-CCCCCAAAGGCTGTGCTGAAACTTGAGC-3'; Reverse: 5'TCATTGTTGTTGGCCTTGAACCTGTAG-3'. The sequences of primer 2 for DNA sequencing (the second Ig domain) were: Forward: 5'-CATCATGCTGAGGTGCCACAGC3'; Reverse: 5'-GATGAGAACAGCGTGTAGCCTATGTTTC-3'. For Fc $\gamma$ RIIa genotype displayed in this study, at amino acid position 27 (located within the first Ig domain), the polymorphic residues are Q: Glutamine, W: Tryptophan; at position 131 (within the second Ig 
domain) the polymorphic residues are $\mathrm{H}$ : Histidine, R: Arginine. For example QW/HR represents heterozygosity at both positions $27(\mathrm{Q} / \mathrm{W})$ and $131(\mathrm{H} / \mathrm{R})$ polymorphic sites.

\section{Analysis of sFc $\gamma$ RIIa in immune-related disease}

To compare levels of sFc $\gamma$ RIIa and sGPVI in plasma from individuals with circulating immune complexes, citrated plasma samples were obtained from consecutively recruited patients with an established diagnosis of RA, or healthy donors. The samples were not matched for age or gender. These samples were obtained with institutional ethics approval at the Mater Misericordiae University Hospital, Dublin, Ireland. People with a history of cardiovascular disease or who were receiving anti-platelet therapy or thromboembolic prophylaxis were excluded.

\section{Statistical analysis}

GraphPad Prism software (version 6.0) was used to apply a two-tailed student's unpaired t-test to compare sFc $\gamma$ RIIa or sGPVI levels between different groups of known Fc $\gamma$ RIIa genotype and a two-tailed Pearson rank was used to analyse correlations between sFc $\gamma$ RIIa and sGPVI. $\mathrm{P}<0.05$ was considered to be statistically significant. ${ }^{* * *} \mathrm{P}<0.001 ;{ }^{* *} \mathrm{P}<0.01 ;{ }^{*} \mathrm{P}<0.05$; ns: not significant.

\section{Results}

\section{sFcrRIIa measurement in plasma by ELISA}

Evidence in the literature indicates that a soluble form of Fc $\gamma$ RIIa (sFc $\gamma$ RIIa) exists in plasma [21]. To measure levels of sFcyRIIa in human plasma of healthy donors or patients with immune-related disease, an ELISA was established using antibodies against separate epitopes within the ectodomain. The ELISA output was reported in relative units, since purified or 
recombinant $\mathrm{sF} \gamma \mathrm{RII}$ a proteins of known concentration were not available to enable calibrating the signal to a standard concentration curve. Serial dilution of sample produced a linear concentration-dependent signal. Serial dilution (from 1 in 2 to 1 in 64) of samples from either normal plasma or supernatant from washed platelets showed a linear relationship with relative light emission (Relative Unit, RLU) (Figure 1), with linear regression analysis for plasma $\left(r^{2}=\right.$ 0.998) and supernatant sample $\left(r^{2}=0.984\right)$ within an acceptable limit. sFc $\gamma$ RIIa levels in plasma from 24 healthy individuals was $0.743 \pm 0.048 \times 10^{6}$ RLU (Mean \pm SE) (data not shown), with a normal range from 0.11 to $1.19 \times 10^{6}$ RLU. The ELISA had a coefficient of variation of $3.8 \%$ and inter-assay variability of less than $10 \%$ indicating acceptable precision. Linear regression equations provided the best fit for the data.

\section{Effect of FcyRIIa polymorphisms on plasma sFcrRIIa levels}

In 24 healthy individuals with known genotype of FcyRIIa, the plasma sFc $\gamma$ RIIa level appeared to be dependent upon genotype (Figure 2A), however as three of the genotypes contained data from only one individual, conclusions from this cohort were limited [31]. Of note, the allele frequency of the W27 variant in this cohort was 0.3125 , which was significantly higher than the minor allele frequency reported in global genetics reference databases (MAF 0.06 to 0.1 ) [32]. The reason for this was not clear but may be related to the heterogeneous ethnicity of the donor group. To improve the statistical power, in subsequent analyses, we grouped data based on occurrence of $\mathrm{HH}$ at position 131. Previous studies demonstrated that the amino acid at position 131 influenced binding affinity of FcyRIIa for IgG complexes [10]. FcyRIIa with a histidine $(\mathrm{H})$ has a higher binding affinity to human $\mathrm{IgG} 2$ than FcyRIIa with an arginine $(\mathrm{R})[4$, 5]. However, in this study, the sFc $\gamma$ RIIa level was not significantly different in non- $131 \mathrm{H}$ and 131H/H (Figure 2B), but was significantly lower in 27W than 27Q (Figure 2C), indicating that 


\section{$\mathrm{sFc} \gamma \mathrm{RIIa}$ release may be distinct from ligand binding and that Fc $\gamma$ RIIa polymorphisms at position 27 and 131 might influence release of sFc $\gamma$ RIIa.}

\section{The mechanism of Fc $\gamma \mathrm{RIIa}$ release from platelets}

Soluble forms of Fc $\gamma$ RIIa have been detected in human serum or plasma [21-23, 33, 34]. Platelets express Fc $\gamma$ RIIa and are a potential source of plasma sFc $\gamma$ RIIa by either secretion of a soluble form of the receptor lacking the transmembrane domain, or proteolytic shedding of the ectodomain from the platelet surface. Previous studies demonstrated that sGPVI is generated from platelet GPVI by metalloproteinase-mediated ectodomain shedding [16] and that engagement of platelet Fc $\gamma$ RIIa also triggered shedding of GPVI [12]. GPVI and Fc $\gamma$ RIIa are structurally analogous members of the immunoreceptor family, and both receptors bind calmodulin within the cytoplasmic domain, a common feature of metalloproteinase-dependent shedding. To test the hypothesis that engagement of Fc $\gamma$ RIIa, induces metalloproteinasemediated ectodomain shedding and releases soluble fragment, human washed platelets were treated with aggregated-IgG $(\mathrm{A}-\mathrm{IgG})$ in the presence or absence of metalloproteinase inhibitor EDTA. Levels of sFcyRIIa or sGPVI were subsequently measured by ELISA. Treatment of washed platelets with A-IgG induced release of sFc $\gamma$ RIIa (Figure 3A), and sGPVI (Figure 3B) with a trend towards dose-dependency. This was consistent with previous studies showing engagement of FcyRIIa or GPVI by their respective ligands triggers both calpain-mediated intracellular cleavage of Fc $\gamma$ RIIa and metalloproteinase-mediated ectodomain shedding of GPVI [12]. The release of sGPVI but not sFc $\gamma$ RIIa was statistically significant. Further, blockade of FcyRIIa by inclusion of IV.3 monoclonal antibody or inclusion of inhibitors of metalloproteinases, calpain or signaling molecules prevented GPVI shedding (Figure 3B), but did not inhibit the generation of sFc $\gamma$ RIIa. This strongly suggested that the mechanism of sFc $\gamma$ RIIa release was different from GPVI shedding (metalloproteinase-mediated). Taken 
together, these data demonstrate that the presence of sFcyRIIa could possibly be driven by a mechanism involving one or more unidentified sheddases, but not by an EDTA-inhibitable metalloproteinase.

\section{FcyRIIa polymorphisms, Fc $\gamma$ RIIa release and GPVI shedding}

In addition to sharing similar structures, both Fc $\gamma$ RIIa and GPVI/FcR $\gamma$ contain an immunoreceptor tyrosine-based activation motif (ITAM) within the cytoplasmic tail involved in signaling transduction. In human platelets treated with agonists acting at either FcyRIIa or GPVI in vitro, there is both intracellular calpain-mediated cleavage of Fc $\gamma$ RIIa (removing the ITAM signaling sequence) and extracellular metalloproteinase-mediated ectodomain shedding of GPVI [12]. In order to examine the relationship between generation of sFc $\gamma$ RIIa and sGPVI in vivo, the respective ELISA assays were used to measure sFc $\gamma$ RIIa and sGPVI in the same plasma samples obtained from healthy individuals. The observed lack of correlation between sFcyRIIa and sGPVI (Figure 4A) is not only consistent with the lack of effect of Fc $\gamma$ RIIa polymorphisms on GPVI shedding (Figure 4B), but also suggests that sFc $\gamma$ RIIa could be derived from other vascular cells, since FcyRIIa is also expressed and shed from neutrophils and monocytes/macrophages [23]. Our previous studies demonstrated that coagulation induces platelet GPVI shedding as sGPVI level was markedly elevated in serum. To assess whether coagulation influences Fc $\gamma$ RIIa release, blood was collected in different anti-coagulants or clotting tube and sFc $\gamma$ RIIa level was measured by ELISA with sGPVI level as a positive control. We showed that unlike elevated serum sGPVI level, sFcrRIIa level in serum is comparable with plasma level in citrate, acid citrate dextrose or EDTA anti-coagulants (data not shown), indicating that unlike GPVI, coagulation did not affect Fc $\gamma$ RIIa release. All these results displayed above revealed that different mechanisms are likely to be involved in release of Fc $\gamma$ RIIa, compared with GPVI release. 


\section{FcyRIIa polymorphisms, release and platelet aggregation}

14A2, a murine monoclonal antibody against CD151, induces platelet activation and aggregation via engagement of FcyRIIa [27]. Platelet aggregation in response to 14A2 contributed to identifying functional differences associated with Fc $\gamma$ RIIa polymorphisms [35]. In the present study, 14A2 at a threshold concentration $(1.0 \mu \mathrm{g} / \mathrm{ml}$, $)$ was used to investigate platelet aggregation and polymorphisms of Fc $\gamma$ RIIa. Based on the time taken to achieve $50 \%$ aggregation, platelet aggregation to 14A2 was divided into quartiles $(+++,++,+,---)$. Among 24 healthy individuals with known genotype of FcyRIIa (Table 1), platelet aggregation in response to $14 \mathrm{~A} 2$ was heterogeneous, consistent with published studies [26, 35]. Standard appropriately powered statistical evaluation approaches could not be used to evaluate genotype and propensity to aggregate, due to three genotypes containing data from a single individual. However, in healthy individuals with $\mathrm{HH}$ at position 131 of Fc $\gamma$ RIIa, platelet aggregation was completely impaired regardless of the polymorphism at 27 , possibly due to the lower binding affinity to murine $\operatorname{IgG}(14 \mathrm{~A} 2)$ for Fc $\gamma \mathrm{RIIa}$ with $\mathrm{HH}$ [10]. However, non-responsiveness to 14A2 was also found in individuals with HR, indicating that other factors, such as copy number or surface density of Fc $\gamma$ RIIa, or genetic variation of the protein tyrosine phosphatase CD148 that regulates ITAM receptor-mediated platelet activation could also contribute to the function of Fc $\gamma$ RIIa [36]. The plasma level of sFc $\gamma$ RIIa under resting conditions was also heterogeneous in individuals with different platelet responses to $14 \mathrm{~A} 2$.

\section{Analysis of sFcrRIIa in immune-related disease}

There is increasing evidence showing the critical role of FcRs in auto-immune disease induced by immune complexes $[1,23,37,38]$, specifically the importance of activating Fc $\gamma$ RIIa in the pathogenesis of RA [39]. Available plasma samples from RA patients, previously used to measure levels of sGPVI, provided an opportunity to apply the new ELISA to measure 
sFc $\gamma$ RIIa levels in the same samples. As seen in Figure 5A, the sFc $\gamma$ RIIa level in RA patients was significantly higher than that of healthy controls, indicating Fc $\gamma$ RIIa may be a potential marker in the pathogenesis of RA, and consistent with previous studies [39]. Plasma sGPVI levels were also significantly higher in RA patients when compared with controls (Figure 5B), revealing platelets might also play a role in this disease. There was no correlation between sFcyRIIa and sGPVI in RA patients (Figure 5C), consistent with data obtained from healthy individuals. These results support the possibility that the release mechanisms for these two receptors are different, further supporting the in vitro studies of shedding mechanisms shown in Figure 3. Unfortunately, genotyping of the RA patients was not possible, and detailed clinical information on the progression and outcomes of disease in different individuals could not be obtained. Nevertheless, findings presented here provide pilot data which would justify expanded future studies of platelet activation and plasma sFc $\gamma$ RIIa analysis in RA using the ELISA and reference data described in this study.

\section{Discussion}

Fc $\gamma$ RIIa is the only IgG-Fc receptor with low affinity expressed on platelets and megakaryocytes. Three RNA splice variants of the FCGR2A gene have been described with Fc $\gamma$ RIIa1 the most widely studied. FcyRIIa2 is secreted or released from human epidermal Langerhans cells [40], neutrophils [23, 34] or thrombin-activated human platelets or a megakaryocytic cell line [22]. Subsequent studies demonstrated that Fc $\gamma$ RIIa2 lacking a hydrophobic segment of the transmembrane exonic sequence was present in human serum [21]. Fc $\gamma$ RIIa3, is identical to Fc $\gamma$ RIIa1 with the addition of a 19-amino acid insertion in the juxtamembrane region of the cytoplasmic tail. However, to date the levels of sFc $\gamma$ RIIa present in normal plasma or in immune-related disease states have not been widely analysed in terms of 
normal variability between individuals or how levels change in immune or other disease states. In this study, an ELISA was developed for quantifying relative levels of sFc $\gamma$ RIIa in human plasma, to analyse the mechanism of sFc $\gamma$ RIIa release from platelets, evaluate the effect of $\mathrm{sFc} \gamma \mathrm{RIIa}$ genotype on function, and increase understanding of sFc $\gamma \mathrm{RIIa}$ as a biomarker and/or role in the pathology of immune-related platelet dysfunction.

Our previous in vitro study showed engagement of either GPVI or Fc $\gamma$ RIIa on platelet by their respective ligands induced both extracellular metalloproteinase-mediated ectodomain shedding of GPVI and intracellular calpain-mediated proteolysis of FcyRIIa [12]. When platelets were treated with A-IgG, release of GPVI (sGPVI) and Fc $\gamma$ RIIa (sFc $\gamma$ RIIa) was detected by ELISA in a dose-dependent manner. From our study, several lines of evidence suggest that the release of $\mathrm{sFc} \gamma \mathrm{RIIa}$ from human platelets is regulated by a different mechanism to that involved in shedding of GPVI. First, A-IgG-induced release of sFc $\gamma$ RIIa from platelets is not inhibited by metalloproteinase inhibitors or by inhibitors of signaling pathways involved in GPVI shedding, consistent with a recent study showing metalloproteinase inhibitor GM6001 and E64d did not affect FcyRIIa shedding from neutrophils after addition of TLR agonists. In this case, TLR agonist-induced FcyRIIa shedding was shown to be dependent on serine proteases, including the pro-protein convertase furin [23]. Second, coagulation induced pronounced shedding of GPVI [41], whereas plasma and serum levels of sFcyRIIa were comparable, consistent with a previous study showing serum and plasma sFc $\gamma$ RIIa levels were similar [21]. Third, there is no apparent correlation between levels of sGPVI and sFcrRIIa in normal healthy plasma, which might have been expected to correlate if common triggers or pathways were involved in regulating their release from platelets. Although in this regard, unlike sGPVI which is only derived from platelets, $\mathrm{sFc} \gamma \mathrm{RIIa}$ may be derived from platelets or other cell types. 
Previous studies demonstrated that the Fc $\gamma$ RIIa polymorphism (H131R) was associated with some autoimmune diseases due to different $\operatorname{IgG}$ binding affinity $[6,7,9]$ and another polymorphism at position 27 (W/Q) did not affect receptor function or IgG binding and was not linked with the polymorphism at position 131 [10]. Regarding the plasma sFc $\gamma$ RIIa level in individuals with different genotype, we showed the sFc $\gamma$ RIIa level was not significantly different between $\mathrm{H} 131 \mathrm{H}$ and non-H131H groups, but is significantly lower in the 27W group, indicating sFcyRIIa release may not depend on ligand binding. Our work indicates that the genotype at positions 27 and 131 influence receptor stability of Fc $\gamma$ RIIa in healthy individuals. These findings provide a potential mechanistic basis for altered responsiveness of platelets to antiplatelet antibodies, and may provide a suitable rationale justifying future studies to evaluate the link between genotype and immune-based platelet defects.

Consistent with previous studies showing FcyRIIa-R131 binds to murine IgG with higher binding affinity than FcyRIIa-H131 $[6,7]$ and that the amino acid at position 27 did not affect receptor function [10], platelet aggregation response to the threshold concentration of 14A2, a murine monoclonal antibody against CD151, was completely impaired in individuals with $\mathrm{H} 131 \mathrm{H}$, regardless of the amino acid at polymorphic position 27 . However, impaired platelet aggregation was also observed in some individuals with H131R, suggesting apart from polymorphism, other factors, such as surface expression of Fc $\gamma$ RIIa, genetic variation of the protein tyrosine phosphatase CD148 could also be involved in FcyRIIa-dependent platelet aggregation [36].

Finally, an ELISA for measuring sFc $\gamma$ RIIa in human plasma should ultimately enable the levels of sFc $\gamma$ RIIa to be evaluated in diseases involving elevated immune complexes. In this study, preliminary analysis of sFcyRIIa in healthy donors and patients with arthritis has shown that plasma levels of sFc $\gamma$ RIIa were significantly higher in RA patients when compared 
with control (healthy donors), indicating Fc $\gamma$ RIIa was involved in the pathogenesis of RA, consistent with previous studies. sFc $\gamma$ RIIa level measured by ELISA may reflect active immune-based arthritis and be predictive of active inflammation. In addition, plasma sGPVI level was also elevated in patients with RA when compared with control, implying platelet and/or collagen receptor GPVI might also be involved in RA, consistent with inflammation amplified by platelet in arthritis via collagen/GPVI-dependent microparticle generation [42]. The elevated sGPVI level might be due to GPVI-dependent platelet activation induced by collagen binding in RA. Unfortunately there was no genomic information available for this RA cohort to evaluate the FcyRIIa polymorphisms. It is worth noting however that other studies have identified an association between the FCGR2A R allele and RA in Europeans $(p=0.020)$, but not in East Asians populations [43], or in a Japanese cohort [44].

In conclusion, it appears that soluble FcyRIIa release results from secretion, possibly dependent on ligand engagement of Fc $\gamma$ RIIa, rather than ectodomain shedding, consistent with Fc $\gamma$ RIIa release from activated human platelets in vitro. Recombinant soluble Fc $\gamma$ RIIa has been previously shown to inhibit Fc-mediated human platelet aggregation in a dose-dependent manner [22]. Therefore, soluble Fc $\gamma$ RIIa released from platelets could be a down-regulation mechanism of platelet function activated via Fc binding in autoimmune disease.

\section{Acknowledgements}

This research was supported by the National Health and Medical Research Council of Australia, National Natural Science Foundation of China (grant no. 81400082), the Natural Science Foundation of Jiangsu Province (BK20140219), the funding for the Distinguished Professorship Program of Jiangsu Province, the Six Talent Peaks Project of Jiangsu Province (WSN-133), the Shuangchuang Project of Jiangsu Province, the 333 projects of Jiangsu 
Province (BRA2017542), the Science and Technology Foundation for the Selected Overseas Chinese Scholars, State Ministry of Human Resources and Social Security.

\begin{abstract}
Author Contributions
JQ performed research and interpreted data; ED and BW developed key reagents and interpreted data; DK, GMM, PMH and KX provided key patient samples and reagents; RKA and EEG designed the research and interpreted the data; all authors co-wrote the manuscript.
\end{abstract}

\title{
Conflicts of Interest
}

All authors have no conflict of interest to declare.

\section{References}

1. Hogarth, P. M. and Pietersz, G. A. (2012) Fc receptor-targeted therapies for the treatment of inflammation, cancer and beyond. Nat Rev Drug Discov 11, 311-31.

2. Qiao, J., Al-Tamimi, M., Baker, R. I., Andrews, R. K., Gardiner, E. E. (2015) The platelet Fc receptor, Fc $\gamma$ RIIa. Immunol. Rev. 268, 241-252.

3. Parren, P. W., Warmerdam, P. A., Boeije, L. C., Arts, J., Westerdaal, N. A., Vlug, A., Capel, P. J., Aarden, L. A., van de Winkel, J. G. (1992) On the interaction of IgG subclasses with the low affinity Fc gamma RIIa (CD32) on human monocytes, neutrophils, and platelets. Analysis of a functional polymorphism to human IgG2. J. Clin. Invest. 90, 1537-46.

4. Salmon, J. E., Edberg, J. C., Brogle, N. L., Kimberly, R. P. (1992) Allelic polymorphisms of human $\mathrm{Fc} \gamma$ receptor IIA and $\mathrm{Fc} \gamma$ receptor IIIB. Independent mechanisms for differences in human phagocyte function. J. Clin. Invest. 89, 1274-81.

5. Tate, B. J., Witort, E., McKenzie, I. F., Hogarth, P. M. (1992) Expression of the high responder/non-responder human Fc $\gamma$ RII. Analysis by PCR and transfection into FcRCOS cells. Immunol. Cell Biol. 70 ( Pt 2), 79-87.

6. Ali, M. M., Elghazali, G., Montgomery, S. M., Farouk, S. E., Nasr, A., Noori, S. I., Shamad, M. M., Fadlelseed, O. E., Berzins, K. (2007) FcyRIIa (CD32) polymorphism and onchocercal skin disease: implications for the development of severe reactive onchodermatitis (ROD). Am. J. Trop. Med. Hyg. 77, 1074-8.

7. Forthal, D. N., Landucci, G., Bream, J., Jacobson, L. P., Phan, T. B., Montoya, B. (2007) Fc $\gamma$ RIIa genotype predicts progression of HIV infection. J. Immunol. 179, 7916-23.

8. Carlsson, L. E., Santoso, S., Baurichter, G., Kroll, H., Papenberg, S., Eichler, P., Westerdaal, N. A. C., Kiefel, V., van de Winkel, J. G. J., Greinacher, A. (1998) Heparin- 
induced thrombocytopenia: new insights into the impact of the FcrRIIa-R-H131 polymorphism. Blood 92, 1526-1531.

9. Rollin, J., Pouplard, C., Cheng Sung, H., Leroux, D., Saada, A., Gouilleux-Gruart, V., Thibault, G., Gruel, Y. (2015) Increased risk of thrombosis in Fc $\gamma$ RIIA 131RR patients with HIT due to defective control of platelet activation by plasma IgG2. Blood 125, 2397-2404.

10. Warmerdam, P. A., van de Winkel, J. G., Vlug, A., Westerdaal, N. A., Capel, P. J. (1991) A single amino acid in the second Ig-like domain of the human Fc $\gamma$ receptor II is critical for human IgG2 binding. J. Immunol. 147, 1338-1343.

11. Flinsenberg, T. W. H., Janssen, W. J., Herczenik, E., Boross, P., Nederend, M., Jongeneel, L. H., Scholman, R. C., Boelens, J.-J., Maas, C., van Gijn, M. E., van Montfrans, J. M., Leusen, J. H., Boes, M. (2014) A novel FcyRIIa Q27W gene variant is associated with common variable immune deficiency through defective Fc $\gamma$ RIIa downstream signaling. Clin. Immunol. 155, 108-117.

12. Gardiner, E. E., Karunakaran, D., Arthur, J. F., Mu, F. T., Powell, M. S., Baker, R. I., Hogarth, P. M., Kahn, M. L., Andrews, R. K., Berndt, M. C. (2008) Dual ITAMmediated proteolytic pathways for irreversible inactivation of platelet receptors: DeITAM-izing Fc $\gamma$ RIIa. Blood 111, 165-174.

13. Qiao, J., Schoenwaelder, S. M., Mason, K. D., Tran, H., Davis, A. K., Kaplan, Z. S., P., J. S., Kile, B. T., Andrews, R. K., Roberts, A. W., Gardiner, E. E. (2013) Low adhesion receptor levels on circulating platelets in patients with lymphoproliferative diseases prior to receiving Navitoclax (ABT-263). Blood 121, 1479-1481.

14. Gardiner, E. E., Al-Tamimi, M., Mu, F. T., Karunakaran, D., Thom, J. Y., Moroi, M., Andrews, R. K., Berndt, M. C., Baker, R. I. (2008) Compromised ITAM-based platelet receptor function in a patient with immune thrombocytopenic purpura. J. Thromb. Haemost. 6, 1175-1182.

15. Stack, J. R., Madigan, A., Helbert, L., Dunne, E., Gardiner, E. E., Andrews, R. K., Finan, R., Smyth, E., Kenny, D., McCarthy, G. M. (2017) Soluble glycoprotein VI, a specific marker of platelet activation is increased in the plasma of subjects with seropositive rheumatoid arthritis. PLoS One 12, e0188027.

16. Gardiner, E. E., Arthur, J. F., Kahn, M. L., Berndt, M. C., Andrews, R. K. (2004) Regulation of platelet membrane levels of glycoprotein VI by a platelet-derived metalloproteinase. Blood 104, 3611-3617.

17. Rabie, T., Strehl, A., Ludwig, A., Nieswandt, B. (2005) Evidence for a role of ADAM17 (TACE) in the regulation of platelet glycoprotein V. J Biol Chem 280, 14462-8.

18. Kahn, J., Walcheck, B., Migaki, G. I., Jutila, M. A., Kishimoto, T. K. (1998) Calmodulin regulates L-selectin adhesion molecule expression and function through a protease-dependent mechanism. Cell 92, 809-18.

19. Cassel, D. L., Keller, M. A., Surrey, S., Schwartz, E., Schreiber, A. D., Rappaport, E. F., McKenzie, S. E. (1993) Differential expression of Fc $\gamma$ RIIA, Fc $\gamma$ RIIB and Fc $\gamma$ RIIC in hematopoietic cells: analysis of transcripts. Mol. Immunol. 30, 451-60.

20. Anania, J. C., Trist, H. M., Palmer, C. S., Tan, P. S., Kouskousis, B. P., Chenoweth, A. M., Kent, S. J., Mackay, G. A., Hoi, A., Koelmeyer, R., Slade, C., Bryant, V. L., Hodgkin, P. D., Aui, P. M., van Zelm, M. C., Wines, B. D., Hogarth, P. M. (2018) The rare anaphylaxis-associated FcrRIIa3 exhibits distinct characteristics from the canonical Fc $\gamma$ RIIa1. Front. Immunol. 9, 1809.

21. Astier, A., Merle-Beral, H., de la Salle, H., Moncuit, J., Cazenave, J. P., Fridman, W. H., Hanau, D., Teillaud, J. L. (1997) Soluble Fc $\gamma$ receptor, Fc $\gamma$ RIIa2, is present in two 
forms in human serum and is increased in patients: with stage $\mathrm{C}$ chronic lymphocytic leukemia. Leuk. Lymphoma 26, 317-26.

22. Gachet, C., Astier, A., de la Salle, H., de la Salle, C., Fridman, W. H., Cazenave, J. P., Hanau, D., Teillaud, J. L. (1995) Release of FcyRIIa2 by activated platelets and inhibition of anti-CD9-mediated platelet aggregation by recombinant Fc $\gamma$ RIIa2. Blood 85, 698-704.

23. Lood, C., Arve, S., Ledbetter, J., Elkon, K. B. (2017) TLR7/8 activation in neutrophils impairs immune complex phagocytosis through shedding of Fc $\gamma$ RIIA. J. Exp. Med. 214, 2103-2119.

24. Ludwig, A., Hundhausen, C., Lambert, M. H., Broadway, N., Andrews, R. C., Bickett, D. M., Leesnitzer, M. A., Becherer, J. D. (2005) Metalloproteinase inhibitors for the disintegrin-like metalloproteinases ADAM10 and ADAM17 that differentially block constitutive and phorbol ester-inducible shedding of cell surface molecules. Comb Chem High Throughput Screen 8, 161-71.

25. Ierino, F. L., Hulett, M. D., McKenzie, I. F., Hogarth, P. M. (1993) Mapping epitopes of human Fc gamma RII (CDw32) with monoclonal antibodies and recombinant receptors. J. Immunol. 150, 1794-1803.

26. Roberts, J. J., Rodgers, S. E., Drury, J., Ashman, L. K., Lloyd, J. V. (1995) Platelet activation induced by a murine monoclonal antibody directed against a novel tetra-span antigen. Br. J. Haematol. 89, 853-60.

27. Ashman, L. K., Aylett, G. W., Mehrabani, P. A., Bendall, L. J., Niutta, S., Cambareri, A. C., Cole, S. R., Berndt, M. C. (1991) The murine monoclonal antibody, 14A2.H1, identifies a novel platelet surface antigen. Br. J. Haematol. 79, 263-70.

28. Looney, R. J., Ryan, D. H., Takahashi, K., Fleit, H. B., Cohen, H. J., Abraham, G. N., Anderson, C. L. (1986) Identification of a second class of IgG Fc receptors on human neutrophils. A 40 kilodalton molecule also found on eosinophils. J Exp Med 163, 82636.

29. Al-Tamimi, M., Mu, F. T., Moroi, M., Gardiner, E. E., Berndt, M. C., Andrews, R. K. (2009) Measuring soluble platelet glycoprotein VI in human plasma by ELISA. Platelets 20, 143-149.

30. Qiao, J., Arthur, J. F., Collecutt, M., Shen, Y., Mu, F. T., Berndt, M. C., Davis, A. K., Andrews, R. K., Gardiner, E. E. (2012) An acquired defect associated with abnormal signaling of the platelet collagen receptor glycoprotein VI. Acta Haematol 128, 233 41.

31. Winters, R., Winters, A., Amedee, R. G. (2010) Statistics: a brief overview. Ochsner J 10, 213-216.

32. The Genomes Project (2018) Database of single nucleotide polymorphisms (dbSNP). National Center for Biotechnology Information, National Library of Medicine, Bethesda, Maryland. https://www.ncbi.nlm.nih.gov/snp/rs139202723

33. Astier, A., de la Salle, H., de la Salle, C., Bieber, T., Esposito-Farese, M. E., Freund, M., Cazenave, J. P., Fridman, W. H., Teillaud, J. L., Hanau, D. (1994) Human epidermal Langerhans cells secrete a soluble receptor for IgG (FcyRII/CD32) that inhibits the binding of immune complexes to Fc $\gamma \mathrm{R}+$ cells. J. Immunol. 152, 201-12.

34. Nagarajan, S., Venkiteswaran, K., Anderson, M., Sayed, U., Zhu, C., Selvaraj, P. (2000) Cell-specific, activation-dependent regulation of neutrophil CD32A ligand-binding function. Blood 95, 1069-77.

35. Mazurov, A. V., Vinogradov, D. V., Vlasik, T. N., Burns, G. F., Berndt, M. C. (1992) Heterogeneity of platelet $\mathrm{Fc}$-receptor-dependent response to activating monoclonal antibodies. Platelets 3, 181-8. 
36. Rollin, J., Pouplard, C., Gratacap, M. P., Leroux, D., May, M. A., Aupart, M., Gouilleux-Gruart, V., Payrastre, B., Gruel, Y. (2012) Polymorphisms of protein tyrosine phosphatase CD148 influence Fc $\gamma$ RIIA-dependent platelet activation and the risk of heparin-induced thrombocytopenia. Blood 120, 1309-16.

37. Takai, T. (2005) Fc receptors and their role in immune regulation and autoimmunity. J Clin Immunol 25, 1-18.

38. Pritchard, N. R., Cutler, A. J., Uribe, S., Chadban, S. J., Morley, B. J., Smith, K. G. (2000) Autoimmune-prone mice share a promoter haplotype associated with reduced expression and function of the Fc receptor FcyRII. Curr. Biol. 10, 227-30.

39. Mullazehi, M., Mathsson, L., Lampa, J., Ronnelid, J. (2006) Surface-bound anti-type II collagen-containing immune complexes induce production of tumor necrosis factor$\alpha$, interleukin-1 $\beta$, and interleukin- 8 from peripheral blood monocytes via Fc $\gamma$ receptor IIA: a potential pathophysiologic mechanism for humoral anti-type II collagen immunity in arthritis. Arthritis Rheum. 54, 1759-71.

40. de la Salle, C., Esposito-Farese, M. E., Bieber, T., Moncuit, J., Morales, M., Wollenberg, A., de la Salle, H., Fridman, W. H., Cazenave, J. P., Teillaud, J. L., et al. (1992) Release of soluble FcyRII/CD32 molecules by human Langerhans cells: a subtle balance between shedding and secretion? J. Invest. Dermatol. 99, 15S-17S.

41. Al-Tamimi, M., Grigoriadis, G., Tran, H., Paul, E., Servadei, P., Berndt, M. C., Gardiner, E. E., Andrews, R. K. (2011) Coagulation-induced shedding of platelet glycoprotein VI mediated by factor Xa. Blood 117, 3912-20.

42. Boilard, E., Nigrovic, P. A., Larabee, K., Watts, G. F., Coblyn, J. S., Weinblatt, M. E., Massarotti, E. M., Remold-O'Donnell, E., Farndale, R. W., Ware, J., Lee, D. M. (2010) Platelets amplify inflammation in arthritis via collagen-dependent microparticle production. Science 327, 580-3.

43. Lee, Y. H., Bae, S. C., Song, G. G. (2015) FCGR2A, FCGR3A, FCGR3B polymorphisms and susceptibility to rheumatoid arthritis: a meta-analysis. Clin. Exp. Rheumatol. 33, 647-54.

44. Kyogoku, C., Tsuchiya, N., Matsuta, K., Tokunaga, K. (2002) Studies on the association of $\mathrm{Fc} \gamma$ receptor IIA, IIB, IIIA and IIIB polymorphisms with rheumatoid arthritis in the Japanese: evidence for a genetic interaction between HLA-DRB1 and FCGR3A. Genes Immun. 3, 488-493. 


\section{Figure legends}

Figure 1. Measurement of sFcyRIIa by ELISA assay. Serial dilution of plasma (A) or supernatant $(\mathrm{S} / \mathrm{N})$ from washed platelets $(\mathrm{B})$ was used to measure the soluble level of Fc $\gamma \mathrm{RIIa}$ by ELISA as described in Methods.

Figure 2. sFc $\gamma$ RIIa levels in healthy individuals with different Fc $\gamma$ RIIa genotype. Plasma or genomic DNA from 24 healthy individuals was used to measure sFc $\gamma$ RIIa level by ELISA and Fc $\gamma$ RIIa genotype by DNA sequencing. (A) Six different alleles of Fc $\gamma$ RIIa were identified. Plasma from healthy individuals with (B) non- $\mathrm{HH}$ and $\mathrm{HH}$ genotype or (C) 27Q and 27W genotypes of Fc $\gamma$ RIIa were used for sFc $\gamma$ RIIa measurement. Unpaired student t-test was used to compare $\mathrm{sFc} \gamma \mathrm{RIIa}$ level with different genotypes. ${ }^{* *} \mathrm{P}<0.01$; ns: not significant.

Figure 3. sFcyRIIa and sGPVI release from platelets. Washed platelets from healthy donors were treated with A-IgG in the presence or absence of EDTA $(10 \mathrm{mM})$, IV.3 $(10 \mu \mathrm{g} / \mathrm{ml})$, GM6001 $(100 \mu \mathrm{M})$, BAY-61 $(5 \mu \mathrm{M})$, E64d $(10 \mu \mathrm{M})$ (all final concentrations) for $3 \mathrm{~h}$ at room temperature and supernatant was isolated to measure soluble forms of (A) Fc $\gamma$ RIIa and (B) GPVI by ELISA. The bars represent mean \pm SEM for triplicate data points. Significant differences from the untreated sample were evaluated using 1-way ANOVA with Dunnett's multiple comparisons test. ${ }^{*} \mathrm{p}<0.05 ;{ }^{* *} \mathrm{p}<0.01 ; * * \mathrm{p}<0.005$.

Figure 4. sGPVI and sFcyRIIa level in healthy individuals. (A) Plasma obtained from 27 healthy individuals was used to evaluate any relationship between sGPVI and sFcyRIIa levels by ELISA. Plasma sGPVI level in healthy individuals with (B) non-HH and HH genotype or (C) non $27 \mathrm{~W} / 131 \mathrm{H}$ and $27 \mathrm{~W} / 131 \mathrm{H}$ genotype of Fc $\gamma R$ III. Unpaired student t-test was used to compare sFcrRIIa level with different genotypes. ns: not significant. 
Figure 5. Levels of sFcyRIIa and sGPVI in plasma from RA patients or healthy donors.

Plasma from RA patients or healthy donors (control) was used to measure (A) sFcrRIIa or (B) sGPVI by ELISA. (C) A correlative analysis of sFc $\gamma$ RIIa and sGPVI in RA patients. ${ }^{* * *} \mathrm{p}<$ $0.001 ;{ }^{* *} \mathrm{p}<0.01$ 
Table 1 Summary of FcyRIIa genotypes in healthy individuals. Fc $\gamma$ RIIa genotype at position 27 and 131, platelet aggregation in response to 14A2 and sFc $\gamma$ RIIa levels in plasma from 24 healthy donors. The ranges of times taken to achieve 50\% aggregation are $<2$ min $(+++), 2-3 \min (++)$ and $\geq 3 \min (+)$ respectively. --- indicated no platelet aggregation in response to $1 \mu \mathrm{g} / \mathrm{ml} 14 \mathrm{~A} 2$ after $20 \mathrm{~min}$. All data were obtained using PRP and were reproducible on different days $(n=2-3)$.

\begin{tabular}{|c|c|c|c|c|c|c|c|}
\hline \multirow[b]{2}{*}{$\mathbf{n}$} & \multicolumn{2}{|c|}{ FcyRIIa genotype } & \multicolumn{4}{|c|}{$\begin{array}{c}\text { Aggregation } \\
(1.0 \mu \mathrm{g} / \mathrm{ml} 14 \mathrm{~A} 2)\end{array}$} & \multirow{2}{*}{$\begin{array}{c}\text { Plasma soluble } \\
\text { Fc } \gamma \text { RIIa } \\
\text { (RLU x 106) (range) }\end{array}$} \\
\hline & 27 & 131 & +++ & ++ & + & --- & \\
\hline 3 & QQ & $\mathrm{HH}$ & & & & 3 & $0.89-1.19$ \\
\hline 1 & QW & $\mathrm{HH}$ & & & & 1 & 0.61 \\
\hline 1 & WW & $\mathrm{HH}$ & & & & 1 & 0.31 \\
\hline 12 & QQ & HR & 1 & 4 & 2 & 5 & $0.49-1.19$ \\
\hline 6 & QW & HR & & 4 & 2 & & $0.32-0.80$ \\
\hline 1 & QQ & RR & & 1 & & & 0.11 \\
\hline
\end{tabular}


Figure 1
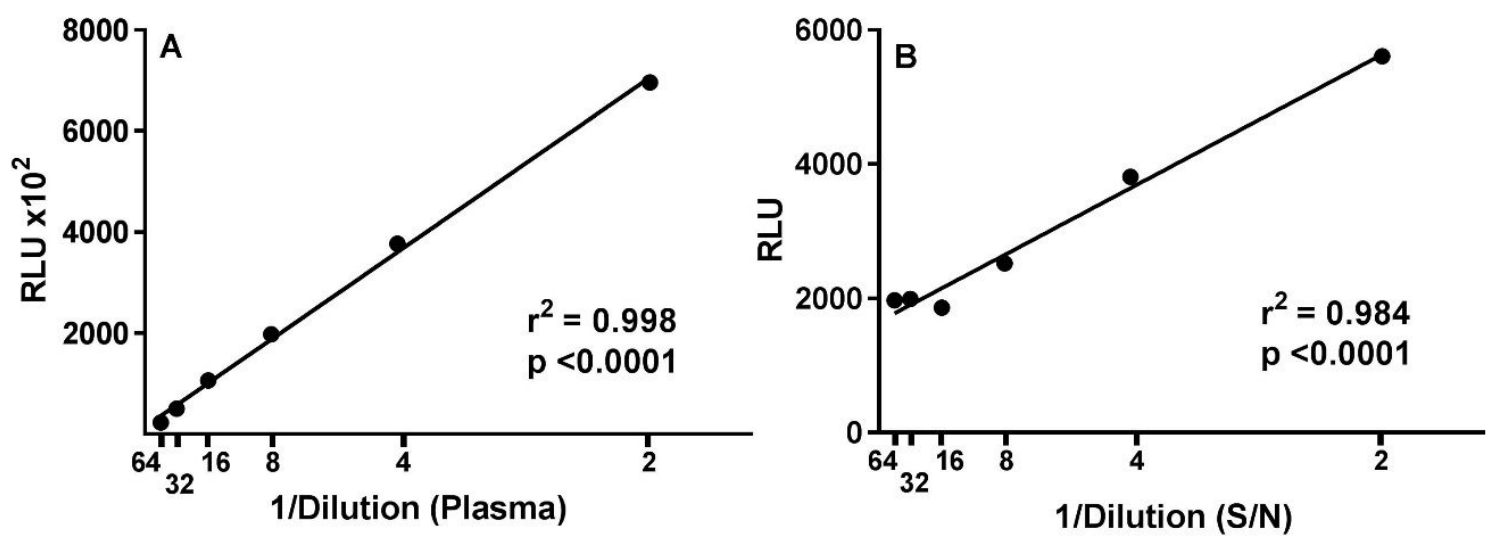
Figure 2
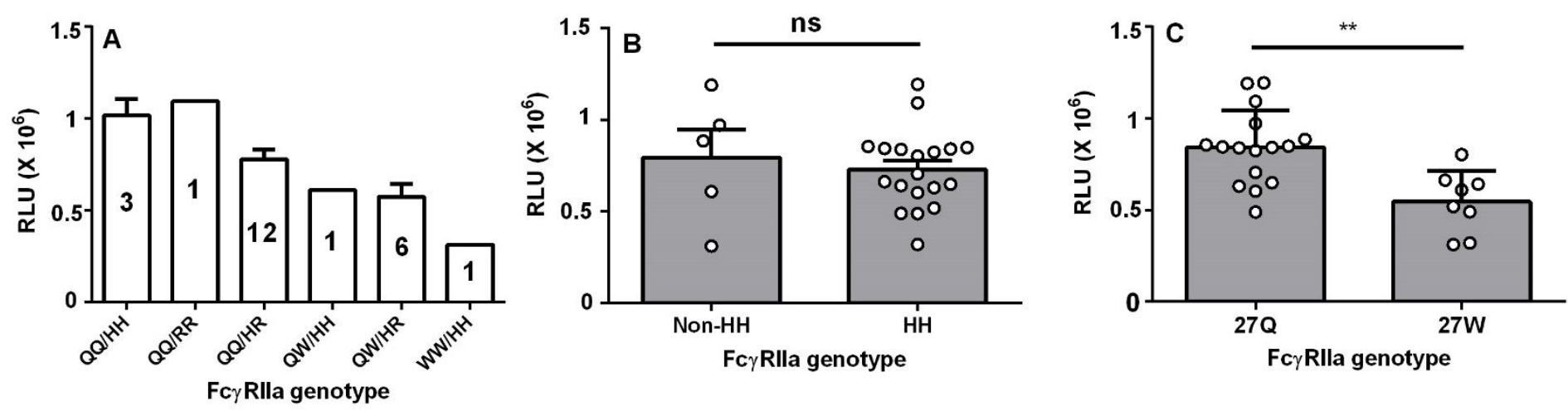

19 
Figure 3
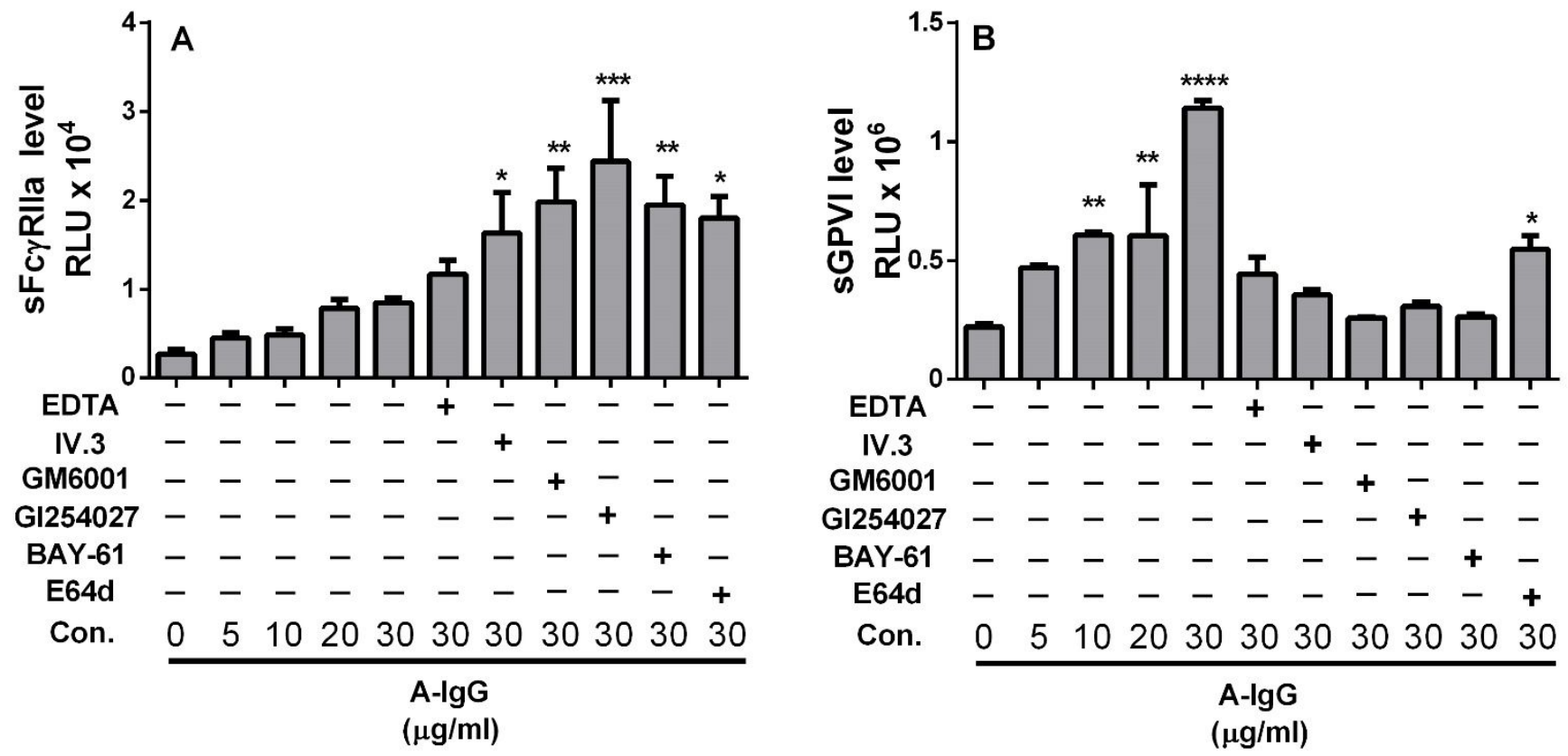
Figure 4
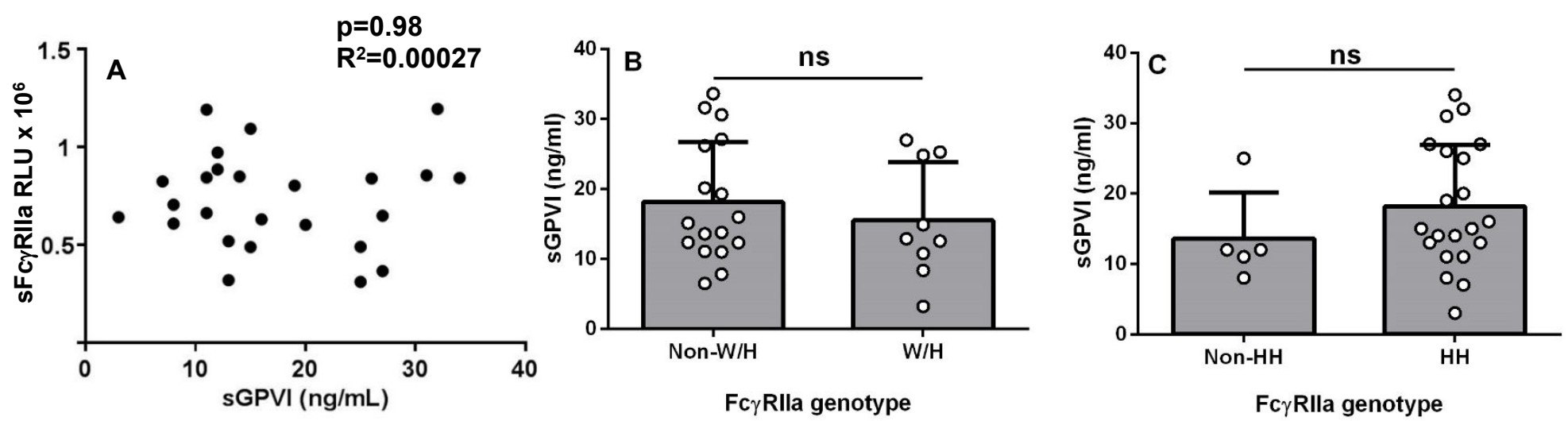

20 
Figure 5
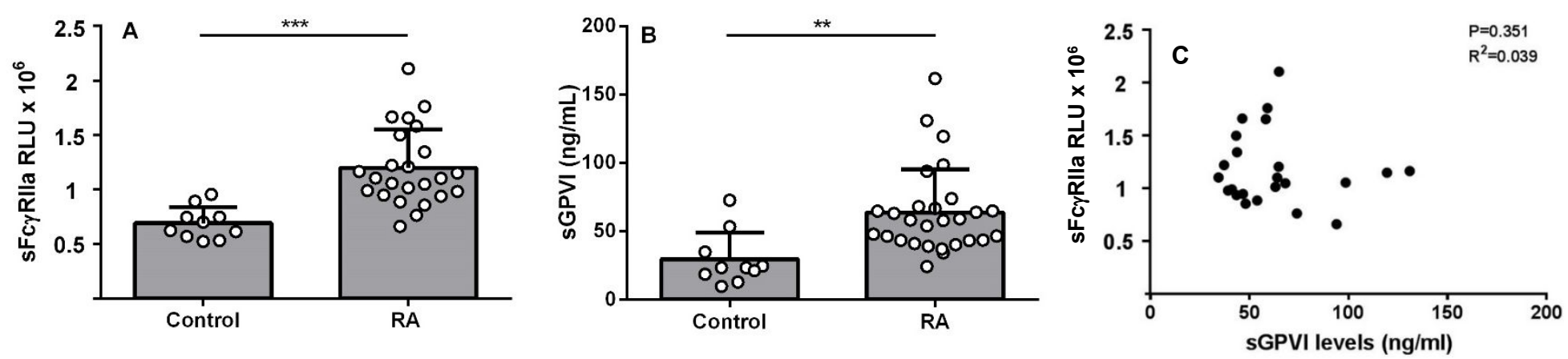